\title{
A Study on Measurement of Forest Soil Redox Potential
}

\author{
Mu Liu ${ }^{1,2}$, Chengde Luo ${ }^{1}$, Xiaoyun Liu $^{2}$, Gang Wan ${ }^{2}$, Bin Dai ${ }^{1}$ \\ ${ }^{1}$ College of Forestry, Sichuan Agricultural University, Ya'an, China; ${ }^{2}$ Promotion Center of Forestry Technology, Forestry Bureau of \\ Fushun County, Fushun, China. \\ Email: lcdya@163.com
}

Received June $5^{\text {th }}, 2013$; revised July $9^{\text {th }}, 2013$; accepted July $28^{\text {th }}, 2013$

Copyright (C) $2013 \mathrm{Mu}$ Liu et al. This is an open access article distributed under the Creative Commons Attribution License, which permits unrestricted use, distribution, and reproduction in any medium, provided the original work is properly cited.

\begin{abstract}
Redox potential has principal influences on formation and attribute of soils, so it is necessary to research the measurement of soil redox potential. The self-made potentiometer and two indigenous FJA-5 potentiometers were employed to measure the Eh values of fir forest soils in situ, which lay in Savage Sea Beauty Spot in Sichuan Province. Simultaneously fresh soils in situ were collected and made into suspensions with various soil-water ratios and standing time to measure Eh values. The results demonstrated that the total tendency of Eh values measured by the self-made potentiometer was gradually falling with soil-water ratios increasing and standing time prolonging. There is a great difference between Eh values measured in laboratory and in situ. Only in situ may the measured Eh values show realistic oxidation-reduction conditions and formation characteristics of forest soil. The self-made potentiometer has a more preferable performance than indigenous FJA-5 potentiometers and it can be applied to measuring forest soil Eh in situ.
\end{abstract}

Keywords: The Self-Made Potentiometer; Redox Conditions; Suspensions; Soil-Water Ratios and Standing Time

\section{Introduction}

Redox reaction is one of the most basic forms of material motion in nature and a vital dynamic phase in soil formation. Redox potential is an intensity index, which decides the direction and extent of redox reaction, and is used for estimating soil's redox ability and showing clearly morphological characteristics and mobile performance of mineral elements in soil profile [1]. So far, Eh value has been mostly measured in soft hydromorphic soils, such as paddy soil [2-11]. For unhydromorphic soils, their Eh values were usually measured after the soil was made into suspensions or disposed else [12-21]. However there are fewer researches on measurement of the forest soil redox potential. The environment and substance composition of soil itself have an extremely profound impact on redox potential, so it is important to research the methods and technologies about measurement of forest soil Eh.

\section{Materials and Methods}

\subsection{Developing Redox Potentiometer Alone}

At present most of redox potentiometers made in China are matched with acidimeters. They are usually used to measuring $\mathrm{pH}$ and $\mathrm{Eh}$ in soil solution. Sometimes they contribute to detect Eh values in paddy soils or other soft sediment. Hence the special redox potentiometer for the forest soil Eh was made by ourselves and its measured results would be compared with the indigenous FJA-5 potentiometers' results.

A self-developed platinum electrode, a commercially available saturated calomel electrode and a DT-9205B multimeter were combinated into the self-made potentiometer (Figure 1). It is necessary to adjust the potential of platinum electrode before measurement so that exact and stable Eh values can be obtained [22-25]. In addition the sand core lies in bottom of saturated calomel electrode should be slightly immersed in saturated $\mathrm{KCl}$ to decrease the disturbance of liquid junction potential as far as possible [26,27].

\subsection{Experimental Design}

There were two experiments, namely, in situ test and laboratory test. In situ test was achieved in Savage Sea Beauty Spot in Sichuan Province, where the soil under fir forest was tested. The soil layer was respectively Layer $\mathrm{A}_{\mathrm{d}}$, the biggest eluvial horizon, and Layer $\mathrm{B}_{2}$, the biggest illuvium. Eh values were measured in February 2011. Electrodes of the self-made potentiometer and FJA-5 potentiometers were inserted in the central section of Layer $A_{d}$ and the electrodes of self-made potentiometer 


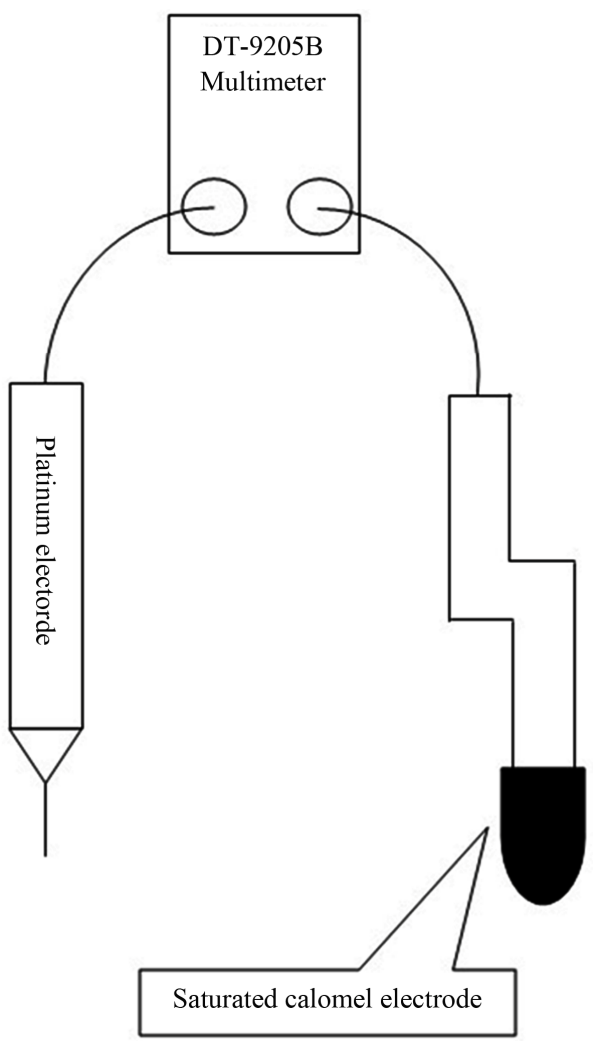

Figure 1. The schematic diagram of the self-made redox potentiometer.

were between that of two FJA-5 potentiometers. And what's more, the distance between platinum electrode and saturated calomel electrode ought to be near (1 - 3 $\mathrm{cm}$ ), which could lower the resistance and determinate error.

Opened the power supply of DT-9205B multimeter linked with the self-made potentiometer and record the numerical value in display screen after it was stable. When the amplitude of fluctuation of the numerical value was less than $1 \mathrm{mv}$ in five minutes, the value was deemed to be stable. Here it was emphasized that the numerical value in display screen only meaned the potential difference between platinum electrode and saturated calomel electrode instead of Eh value. The Eh value must be the summation of this potential difference and the constant potential provided by saturated calomel electrode at corresponding temperature. Simultaneously opened the power supply of FJA-5 potentiometers and the numerical value in display screen was exactly the Eh value. After finishment of Eh measurement in Layer $A_{d}$, all electrodes were taken out and washed by distilled water, then they were cleaned by dry filter papers to continue measuring Eh values of Layer $\mathrm{B}_{2}$ with the same method. Eh values of each layer were repeatedly measured three times. Furthermore fresh soil of both Layer $A_{d}$ and Layer $\mathrm{B}_{2}$ were collected, preserved with fresh-keep- ing packaging and brought back to laboratory.

$10 \mathrm{~g}$ fresh soil samples were weighed and put in 50-ml beakers with high pattern in which additional distilled water with different volumes were mixed and suspendsions with different soil-water ratios were formed. These suspensions had five soil-water ratios together, that was, $1: 1,1: 2,1: 3,1: 4$ and 1:5. As far as they were formed, the standing time was began to be recorded, which was respectively $0,1,2,6,12,24,48,96,144,192$ and 240 hours. Then Eh values were measured under varied soilwater ratio and standing time by the self-made potentiometer and FJA-5 potentiometers. As same as in situ test, Eh values were repeatedly measured three times. At last average values were worked out to draw the curve graph where Eh values were changing with changed soilwater ratios and standing time.

\section{Results and Discussion}

\subsection{Laboratory Analysis}

The Eh values measured by the self-made potentiometer were gradually falling with soil-water ratios increasing and standing time prolonging (Figure 2), whereas the Eh values measured by FJA-5 potentiometers were sometimes high and sometimes low, and irregular (Figures 3 and 4). The approximate tendency of Eh values of various suspensions with incremental soil-water ratios and prolonged standing time could be analysed according to Nernst Equation

$$
E h=E^{0}+\frac{R T}{n F} L O G \frac{O X}{R E D}
$$

If soil-water ratio is smaller, the concentration of redox systems in soil is higher, the oxidizing matters' oxidation capability is more powerful, even the concentration of oxidizing matters $(O X)$ is greater than that of re-

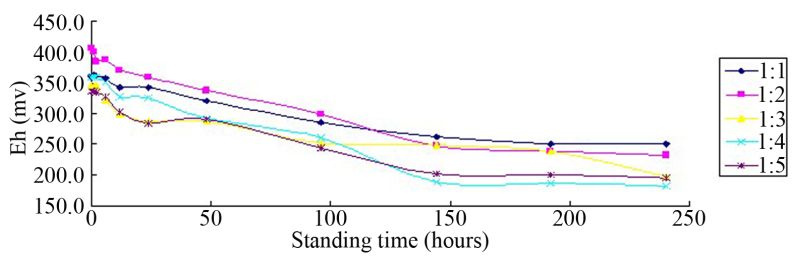

(a)

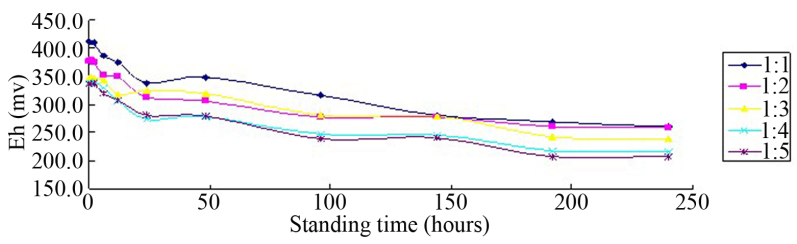

(b)

Figure 2. The variational curves of Eh values in Layer $A_{d}$ (a) and Layer $B_{2}(b)$ measured by the self-made potentiometer. 1:1, 1:2, 1:3, 1:4 and 1:5 were the soil-water ratios. 


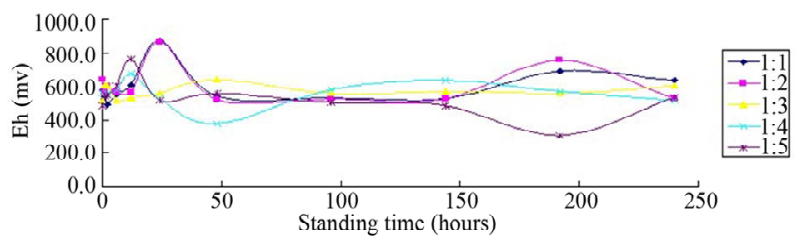

(a)

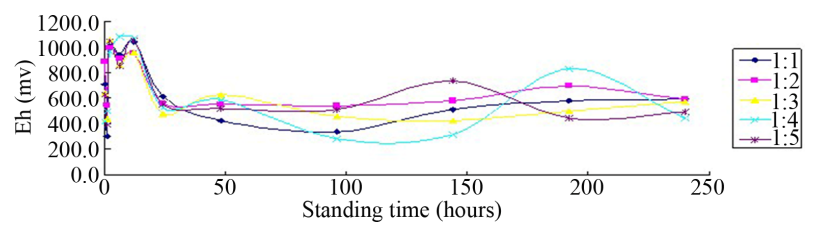

(b)

Figure 3. The variational curves of Eh values in Layer $A_{d}$ (a) and Layer $B_{2}(b)$ measured by the first FJA-5 potentiometer. 1:1, 1:2, 1:3, 1:4 and 1:5 were the soil-water ratios.

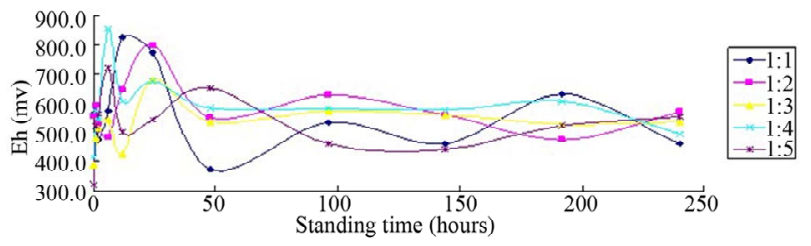

(a)

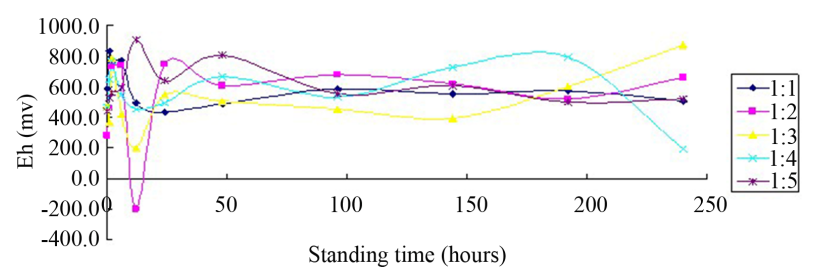

(b)

Figure 4. The variational curves of Eh values in Layer $A_{d}(a)$ and Layer $B_{2}$ (b) measured by the second FJA-5 potentiometer. 1:1, 1:2, 1:3, 1:4 and 1:5 were the soil-water ratios.

ducing matters $(R E D)$, then the Eh value is higher. However, with soil-water ratio amplifying, the concentration of redox systems is decreasing little by little, the reducing matters' reduction capability is just improving and this moment the concentration of reducing matters $(R E D)$ will exceed the oxidizing matters $(O X)$, as a result the Eh value is falling by degress. Furthermore soil is isolated from the atmosphere outside more and more seriously when standing time is infinitely prolonging, the reduction condition is more and more superior, and then the concentration of reducing matters (RED) is more and more greater. Thereupon the Eh value will be more and more lower.

From what had been analysed above, the approximate tendency of Eh values measured by the self-made potentiometer was coincident with the consequence deduced from Nernst Equation, while the total trend of Eh values detected by FJA-5 potentiometers was not. Willis (1932), Quispel (1947) and Bohn (1968) considered consensually that Eh was related to water levels, moisture content, soil structure and the amount of oxidational and reducible materials as well as it was only possible to detect oxidation-reduction conditions in soils when the measurements were carried out in situ after making Eh measurements on soil pastes or suspensions $[18,29,30]$.

\subsection{In Situ Analysis}

Eh values measured in situ were showed by Table 1. In order to examine the precision and reappearance, coefficient of variation was employed. It was noticed that ' 0 ' (Table 1) should not be involved in averaging when calculating coefficient of variation.

It was clear in Table 1 that coefficient of variation of Eh values got from the self-made potentiometer was much less than $1 \%$, while that of values got from FJA-5 potentiometers was much bigger. Thus it was considered that the measurement results of the self-made potentiometer had relatively higher precision and better reappearance.

Soil redox potential is closely related to moisture, porosity, ventilated extent and content of organic matter $[1,6,9]$, so them of soil in situ were revealed in Table 2 . Seen from which, the contents of moisture and organic matter in Layer $A_{d}$ were obviously higher than that of Layer $\mathrm{B}_{2}$, as well as porosity and ventilated extent were smaller than that of Layer $B_{2}$, thereupon the Eh value of Layer $A_{d}$ ought to be lower than Layer $B_{2}$. From what Table 1 showed, the Eh values of Layer $A_{d}$ measured by the self-made potentiometer were all lower than Layer $\mathrm{B}_{2}$, while the results got from FJA-5 potentiometers were

Table 1. Soil Eh values measured in situ.

\begin{tabular}{cccccc}
\hline Soil Layer & \multicolumn{3}{c}{ Eh Values, mv } & & $\begin{array}{c}\text { Coefficient of } \\
\text { Variation, \% }\end{array}$ \\
\hline $\mathrm{A}_{\mathrm{d}}$ & $\triangle$ & 585.6 & 384.7 & 595.2 & 22.78 \\
& $\circ$ & 386.1 & 385.1 & 386.1 & 0.15 \\
& $\nabla$ & 520.6 & 459.7 & 0 & 8.59 \\
$\mathrm{~B}_{2}$ & $\triangle$ & 323.7 & 285.5 & 337.4 & 8.52 \\
& $\circ$ & 494.8 & 494.8 & 493.8 & 0.12 \\
& $\nabla$ & 377.9 & 311.3 & 0 & 9.66 \\
\hline
\end{tabular}

$\triangle$, Eh values measured by the first FJA-5 potentiometer; $\circ$, Eh values measured by the self-made potentiometer; $\nabla$, Eh values measured by the second FJA-5 potentiometer.

Table 2. Soil moisture, porosity, ventilated extent and contents of organic matter.

\begin{tabular}{ccccc}
\hline $\begin{array}{c}\text { Soil } \\
\text { Layer }\end{array}$ & Moisture, \% & Porosity, \% & $\begin{array}{c}\text { Ventilated } \\
\text { Extent, \% }\end{array}$ & $\begin{array}{c}\text { Contents of } \\
\text { Organic Matter, \% }\end{array}$ \\
\hline $\mathrm{A}_{\mathrm{d}}$ & 33.64 & 40.6 & 22.77 & 5.3556 \\
$\mathrm{~B}_{2}$ & 12.35 & 49.72 & 28.65 & 1.3484 \\
\hline
\end{tabular}


opposite. It has been proved that oxidation processes occupy primary superiority in formation of forest soil, however moisture and organic matter often accumulate in surface layer so that redox potential of surface soil will be lower than that of bottom soil [31]. This difference may vary from several or dozens of millivolts to hundreds of millivolts. Usually there is a buffer slightly influenced by moisture and organic matter below Layer $A_{1}$, such as Layer $A_{d}$ [31]. In summary, Eh values measured by the self-made potentiometer could objectively reflect the oxidation-reduction conditions and formation characteristics of forest soil in field.

The significance of difference between Eh values measured by the self-made potentiometer and by FJA-5 potentiometers was tested. Similarly "0" (Table 1) should not be involved in averaging and the test results were displayed in Table 3. It was found in Table 3 that the interclass differences $(\triangle \& \nabla)$ were not significant $(P>0.05)$ regardless of Layer $A_{d}$ or $B_{2}$, while in interblock differences, except that the difference between Eh values of Layer $A_{d}$ measured by the self-made potentiometer and by the first FJA-5 potentiometer $(\circ \& \triangle)$ was not significant $(P>0.05)$, the others were very significant $(P<0.01)$. This test manifested that the measurement results of the self-made potentiometer had higher precision and accuracy than FJA-5 potentiometers. The measurement results obtained from FJA-5 potentiometers were hardly able to reflect the oxidation-reducetion conditions and formation characteristics of soil in field.

To move forward a single step, significance of differences between Eh values measured in situ and in laboratory by the self-made potentiometer were tested. The result demonstrated that there was a significant $(P<0.05)$ or very significant difference $(P<0.01)$ between Eh values measured in situ and at each soil-water ratio and standing time in Layer $A_{d}$ (Appendix 1), and that for Layer $\mathrm{B}_{2}$, only exsited very significant difference $(P<$ 0.01) (Appendix 2). So it is safely concluded that if for-

Table 3. Significance of differences of Eh values.

\begin{tabular}{|c|c|c|c|c|c|}
\hline Soil Layer & Source of & Variation & $\mathrm{F}$ & P-value & F crit \\
\hline \multirow[t]{3}{*}{$\mathrm{A}_{\mathrm{d}}$} & Interblock & $\circ \& \triangle$ & 3.9554 & 0.1176 & 7.7086 \\
\hline & & $\circ \& \nabla$ & $35.5390^{* *}$ & 0.0039 & 7.7086 \\
\hline & Interclass & $\triangle \& \nabla$ & 0.1959 & 0.6809 & 7.7086 \\
\hline \multirow[t]{3}{*}{$\mathrm{B}_{2}$} & Interblock & $\circ \& \triangle$ & $136.7974^{* *}$ & 0.0003 & 7.7086 \\
\hline & & $\circ \& \nabla$ & $55.9376^{* *}$ & 0.0017 & 7.7086 \\
\hline & Interclass & $\triangle \& \nabla$ & 1.4266 & 0.2983 & 7.7086 \\
\hline
\end{tabular}

$\triangle$, Eh values measured by the first FJA-5 potentiometer; $\circ$, Eh values measured by the self-made potentiometer; $\nabla$, Eh values measured by the second FJA-5 potentiometer; ${ }^{* *}$ Significance of difference is at the $P<0.01$ level. est soils are brought back to laboratory and made into suspensions for redox potential, there will be a great difference compared with the measurement in situ and the Eh values measured in suspensions cannot completely reflect the actual oxidation-reduction conditions of forest soil.

\section{Conclusions}

For resreaches on redox process of unhydromorphic soils such as forest soil, if soil samples are made into suspensions, their Eh values will change with changed soilwater ratio and standing time and it is difficult to determine appropriate soil-water ratio and standing time. The Eh values measured at varied soil-water ratio and standing time have significant or very significant differences with that measured in situ. So Eh measurement in situ should be gradually promoted.

The methods and technologies about measurement of unhydromorphic soil Eh in situ still need to face a lot of problems and challenges in study on soil electrochemistry. Through preliminary analysis on Eh values measured in situ and in laboratory, it can be definitely deemed that the measurement results of the self-made potentiometer have relatively higher precision and accuracy and that the self-made potentiometer can be applied to measuring forest soil Eh in situ.

\section{Acknowledgements}

The authors thank Prof. Yongxin Zhan and Prof. Liang Zhao (Department of Physics, College of Life and Basic Sciences, Sichuan Agricultural University) for guiding make of redox potentiometer.

\section{REFERENCES}

[1] Q. Y. Huang, "Soil Science," Agricultural Press in China, Beijing, 2006.

[2] W. E. Connell and W. H. Patrick, "Sulfate Reduction in Soil: Effects of Redox Potential and pH," Science, Vol. 59, No. 3810, 1968, pp. 86-87. doi:10.1126/science. 159.3810 .86

[3] S. Gotoh and W. H. Patrick, "Transformation of Manganese in a Waterlogged Soil as Affected by Redox Potential and pH," Soil Science Society of America Journal, Vol. 36, No. 5, 1972, pp. 738-742. doi:10.2136/sssaj1972.03615995003600050018x

[4] S. Gotoh and W. H. Patrick, "Transformation of Iron in a Waterlogged Soil as Influenced by Redox Potential and pH," Soil Science Society of America Journal, Vol. 38, No. 1, 1974, pp. 66-71. doi:10.2136/sssaj1974.03615995003800010024x

[5] A. X. Hou, G. X. Chen and Z. P. Wang, "Methane and Nitrous Oxide Emissions from a Rice Field in Relation to Soil Redox and Microbiological Processes," Soil Science Society of America Journal, Vol. 64, No. 6, 2000, pp. 
2180-2186. doi:10.2136/sssaj2000.6462180x

[6] L. N. Mandal, "Levels of Iron and Manganese in Soil Solution and the Growth of Rice in Water-Logged Soils in Relation to the Oxygen Status of Soil Solution," Soil Science, Vol. 94, No. 6, 1962, pp. 387-391. doi:10.1097/00010694-196212000-00006

[7] W. H. Patrick, "Nitrate Reduction Rates in a Submerged Soil as Affected by Redox Potential," Transactions 7th Inernational Congress of Soil Science, Vol. 2, 1960, pp. 494-500.

[8] W. H. Patrick and A. Jugsujinda, "Sequential Reduction and Oxidation of Inorganic Nitrogen, Manganese and Iron in Flooded Soil," Soil Science Society of America Journal, Vol. 56, No. 4, 1992, pp. 331-332. doi:10.2136/sssaj1992.03615995005600040011x

[9] K. R. Reddy and W. H. Patrick, "Effect of Alternate Aerobic and Anaerobic Conditions on Redox Potential, Organic Matter Decomposition and Nitrogen Loss in a Flooded Soil," Soil Biology \& Biochemistry, Vol. 7, No. 2, 1975, pp. 87-94. doi:10.1016/0038-0717(75)90004-8

[10] A. Swarup, "Influence of Organic Matter and Flooding on the Chemical and Electrochemical Properties of Sodic Soil and Rice Growth," Plant and Soil, Vol. 106, No. 1, 1988, pp. 135-141. doi:10.1007/BF02371205

[11] Z. P. Wang, R. D. De Laune and W. H. Patrick, "Soil Redox and $\mathrm{pH}$ Effects on Methane Production in a Flooded Rice Soil," Soil Science Society of America Journal, Vol. 57, No. 2, 1993, pp. 382-385. doi:10.2136/sssaj1993.03615995005700020016x

[12] T. R. Yu, "The Electrochemical Properties and Methodology of Soil," Science Press, Beijing, 1976.

[13] C. Y. Huang, "Instructors on Soil Experiment and Practice," Agricultural Press in China, Beijing, 1992.

[14] C. J. Li, S. S. Li, S. Chen, et al., "Research on Eh-pH of Granite in Jiaocheng City of Shanxi Province," Hydrogeology and Engineering Geology, No. 5, 1998, pp. 4345.

[15] Z. Li, Y. Wang and J. Kong, "A Study on Measurement of Soil Redox Potential," Environmental Science and Management, Vol. 33, No. 10, 2008, pp. 172-174.

[16] K. Marie, P. H. Masscheleyn and C. W. Lindau, "Production of Dinitrogen and Nitrous Oxide in Soil Suspensions as Affected by Redox Potential," Water, Air and Soil Pollution, Vol. 61, No. 1-2, 1992, pp. 37-45. doi:10.1007/BF00478364

[17] W. H. Patrick, B. G. Williams and J. T. Moraghan, "A Simple System for Controlling Redox Potential and $\mathrm{pH}$ in Soil Suspensions," Soil Science Society of America Journal, Vol. 37, No. 2, 1973, pp. 331-332. doi:10.2136/sssaj1973.03615995003700020048x

[18] A. Quispel, "Measurement of the Oxidation-Reduction Potentials of Normal and Inundated Soils," Soil Science, Vol. 63, No. 4, 1947, pp. 265-275. doi:10.1097/00010694-194704000-00002

[19] L. Z. Tang, K. Haibara, H. Toda, et al., "Transformation of $\mathrm{Fe}^{2+}$, Eh and pH Values of Forest Soil in Wet Land," Acta Ecologica Sinica, Vol. 25, No. 1, 2005, pp. 103-107.

[20] G. H. Willis, R. C. Wander and L. M. Southwick, "Degradation of Trifluralin in Soil Suspensions as Related to Redox Potential," Journal of Environmental Quality, Vol. 3, No. 3, 1974, pp. 262-265. doi:10.2134/jeq1974.00472425000300030016x

[21] K. Yu, Z. Wang and A. Vermoesen, "Nitrous Oxide and Methane Emissions from Different Soil Suspensions: Effect of Soil Redox Status," Biology and Fertility of Soils, Vol. 34, No. 1, 2001, pp. 25-30. doi: $10.1007 / \mathrm{s} 003740100350$

[22] C. Carrie, J. Wafer, R. Barrett, et al., "Construction of Platinum-Tipped Redox Probes for Determining Soil Redox Potential," Journal of Environmental Quality, Vol. 33, No. 6, 2004, pp. 2375-2379. doi: $10.2134 /$ jeq2004.2375

[23] B. Eric-Van, B. Suzanne and T. Georges, "Continuous Multiple Measurement of Soil Redox Potential Using Platinum Microelectrode," Soil Science Society of America Journal, Vol. 66, No. 6, 2002, pp. 1813-1820. doi:10.2136/sssaj2002.1813

[24] S. Fiedler, M. J. Vepraskas and J. L. Richardson, "Soil Redox Potential: Importance, Field Measurements and Observations," Academic Press, Ireland, 2007.

[25] W. H. Patrick, R. P. Gambrell and S. P. Faulkner, "Redox Measurements of Soils,” In: D. L. Sparks and A. L. Page, Eds., Methods of Soil Analysis. Part 3. Chemical Methods, Soil Science Society of America, WI, Madison, 1996, pp. 1358-1390.

[26] S. Du and X. Z. Gao, "Regulations on Technology of Soil Analysis," Agricultural Press in China, Beijing, 2006.

[27] W. L. Si, "Analysis and Discussion on Frequently Asked Questions in Soil Eh Measurement," Sinkiang Science and Technology of Oil, Vol. 7, No. 2, 1997, pp. 68-69.

[28] S. D. Zhao, "General Chemistry," Agricultural Press in China, Beijing, 2007.

[29] L. G. Willis, "Oxidation-Reduction Potentials and the Hydrogen Ion Concentration of a Soil," Spanish Journal of Agricultural Research, Vol. 45, No. 1, 1932, pp. 571575.

[30] H. L. Bohn, "Electromotive Forces of Inert Electrodes in Soil Suspensions," Soil Science Society of America Process, Vol. 32, No. 2, 1968, pp. 211-215. doi:10.2136/sssaj1968.03615995003200020019x

[31] T. R. Yu and Z. C. Chen, "Chemical Processes in Soil Formation,” Science Press, Beijing, 1990. 


\section{Appendix 1}

Significance of differences between Eh values measured in situ and in laboratory (Layer $A_{d}$ ).

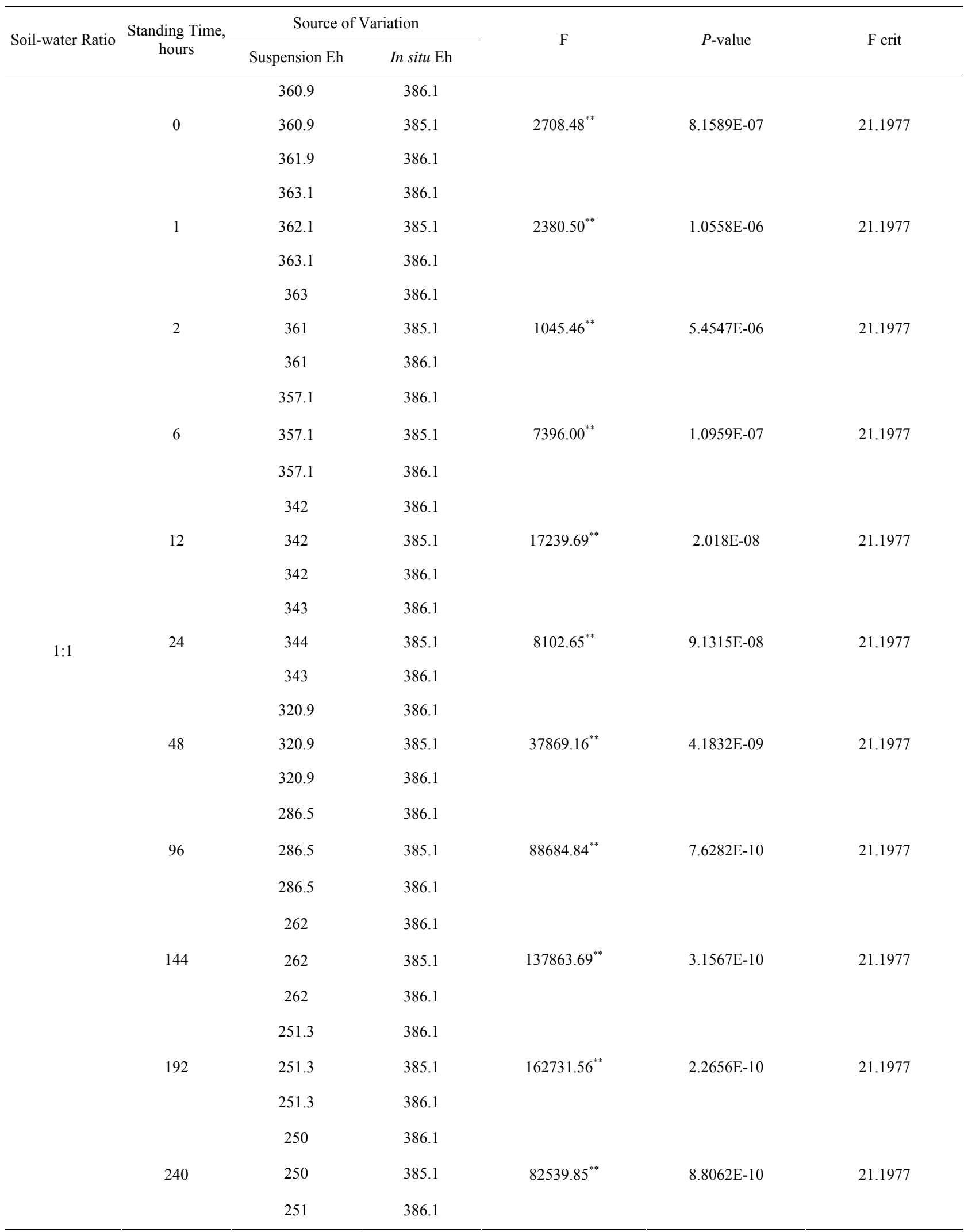




\section{Continued}

0

407.2

386.1

407.2

385.1

$4134.49^{* *}$

3.50435E-07

21.1977

407.2

386.1

402

386.1

402

385.1

$2371.69^{* *}$

1.06369E-06

21.1977

402

386.1

384.7

386.1

2

384.7

385.1

$10.24^{*}$

0.03290081

21.1977

384.7

386.1

388

386.1

6

389

385.1

$37.84^{* *}$

0.00354206

21.1977

$389 \quad 386.1$

371.7

386.1

12

371.7

385.1

$1780.84^{* *}$

$1.88485 \mathrm{E}-06$

21.1977

371.7

386.1

360

386.1

$1: 2$

24

361

385.1

$2910.85^{* *}$

7.06511E-07

21.1977

360

386.1

338.1

386.1

48

338.1

385.1

$10082.00^{* *}$

5.8989E-08

21.1977

339.1

386.1

298

386.1

96

299

385.1

$34138.85^{* *}$

5.14717E-09

21.1977

299

386.1

247.2

386.1

144

247.2

385.1

$172806.49^{* *}$

2.00916E-10

21.1977

247.2

386.1

238

386.1

192

238

385.1

$196514.89^{* *}$

$1.55362 \mathrm{E}-10$

21.1977

238

386.1

231.3

386.1

240

231.3

385.1

$214739.56^{* *}$

1.30111E-10

21.1977

386.1 


\section{Continued}

$1: 3$

24

48

144

192

240
386.1

0 346.1

346.1

385.1

386.1

346.1

344

345

345

346.2

346.2

345.2

323.3

323.3

323.3

298

298

299

287.3

287.3

287.3

288

287

287

252.6

252.6

252.6

249

250

250

238.4

238.4

238.4

197

197

197

386.1

385.1

386.1

386.1

385.1

386.1

386.1

385.1

386.1

386.1

385.1

386.1

386.1

385.1

386.1

386.1

385.1

386.1

386.1

385.1

386.1

386.1

385.1

386.1

386.1

385.1

386.1

386.1

385.1
$34400.65^{* *}$

5.06914E-09

21.1977

$87261.16^{* *}$

7.87909E-10

21.1977

$43601.05^{* *}$

3.15567E-09

21.1977

$159600.25^{* *}$

2.35541E-10

21.1977

$83354.45^{* *}$

8.63493E-10

21.1977

$195452.41^{* *}$

$1.57056 \mathrm{E}-10$

21.1977

$320695.69^{* *}$

5.83386E-11

21.1977 


\section{Continued}

1:4

24

48

96

6

12

0

1

2

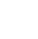

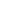

359.6

359.6

359.6

359.6

359.6

359.6

360

360

359

351.8

351.8

351.8

327

327

327

326

327

326

291.8

291.8

291.8

262

261

261

188.7

144

188.7

188.7

186

192

240

187

183.1
386.1

385.1

386.1

386.1

385.1

$6162.25^{* *}$

$1.57835 \mathrm{E}-07$

21.1977

386.1

386.1

385.1

$3065.45^{* *}$

$6.37119 \mathrm{E}-07$

21.1977

386.1

386.1

385.1

$10383.61^{* *}$

$5.56129 \mathrm{E}-08$

21.1977

386.1

386.1

385.1

$31081.69^{* *}$

6.20939E-09

21.1977

386.1

386.1

385.1

$15895.45^{* *}$

2.37369E-08

21.1977

386.1

386.1

385.1

$79467.61^{* *}$

$9.50024 \mathrm{E}-10$

21.1977

386.1

386.1

385.1

$69676.45^{* *}$

1.23577E-09

21.1977

386.1

386.1

385.1

$349517.44^{* *}$

4.9114E-11

21.1977

386.1

386.1

385.1

$178383.65^{* *}$

$1.88549 \mathrm{E}-10$

21.1977

386.1

385.1

$186050.00^{* *}$

$1.73331 \mathrm{E}-10$

21.1977

182.1

386.1 


\section{Continued}

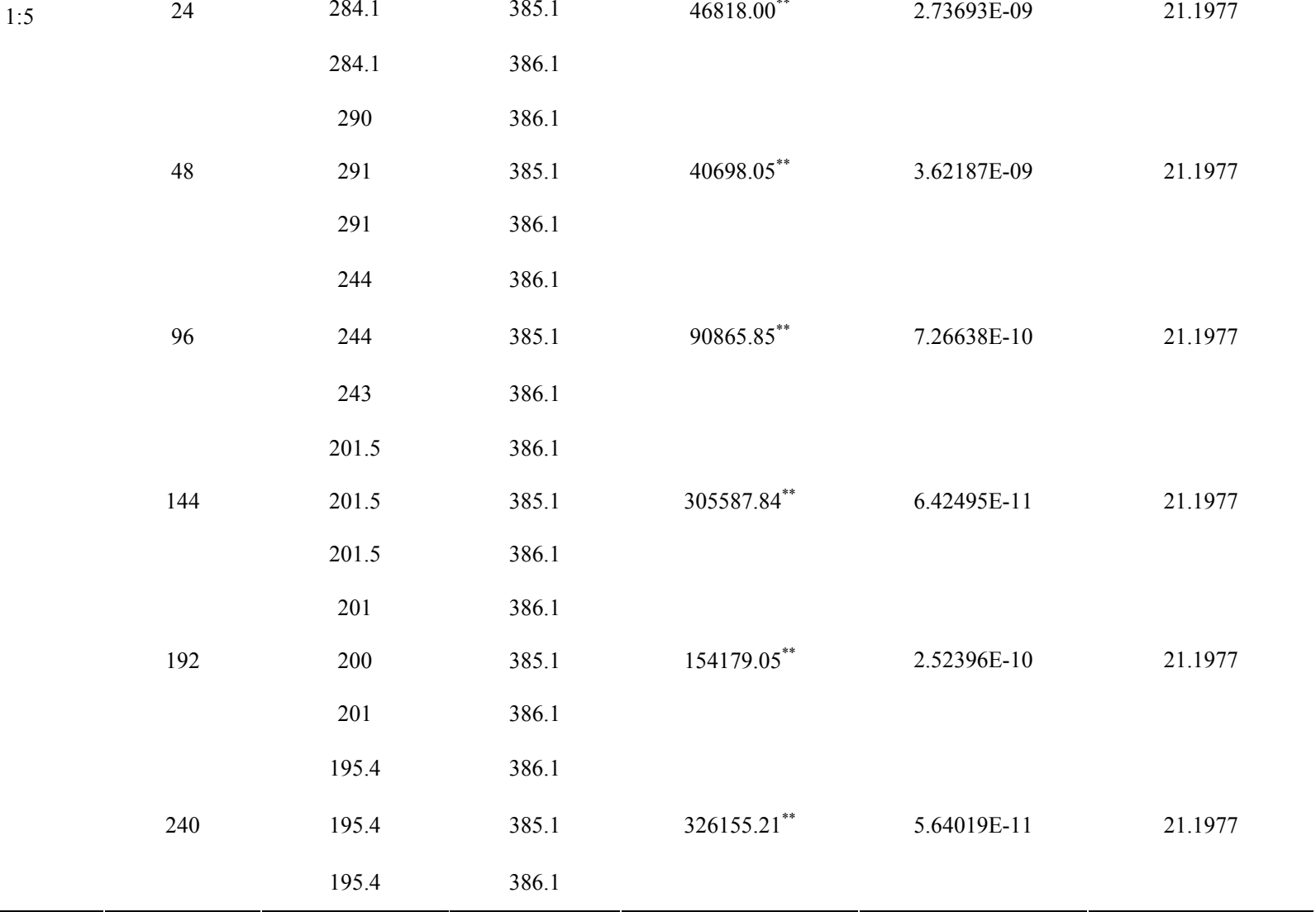

0

335.3

335.3

335.3

337.2

1

2

6

12

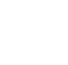

$1: 5$

336.2

327.5

302.4

302.4

302.4

283.1

386.1

385.1

386.1

386.1

385.1

$10760.45^{* *}$

5.17871E-08

21.1977

386.1

386.1

385.1

$23195.29^{* *}$

$1.11488 \mathrm{E}-08$

21.1977

386.1

386.1

385.1

$30555.04^{* *}$

6.42526E-09

21.1977

386.1

386.1

385.1

$62550.01^{* *}$

$1.53338 \mathrm{E}-09$

21.1977

386.1

386.1

385.1

$46818.00^{* *}$

.

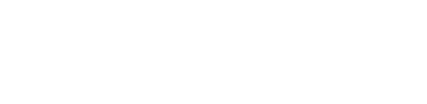




\section{Appendix 2}

Significance of differences between Eh values measured in situ and in laboratory (Layer $\mathbf{B}_{2}$ ).

\begin{tabular}{|c|c|c|c|c|c|c|}
\hline \multirow{2}{*}{ Soil-water Ratio } & \multirow{2}{*}{$\begin{array}{l}\text { Standing Time, } \\
\text { hours }\end{array}$} & \multicolumn{2}{|c|}{ Source of Variation } & \multirow{2}{*}{$\mathrm{F}$} & \multirow{2}{*}{$P$-value } & \multirow{2}{*}{$\mathrm{F}$ crit } \\
\hline & & Suspension Eh & In situ Eh & & & \\
\hline & & 412.1 & 494.8 & & & \\
\hline & 0 & 411.1 & 494.8 & $30776.81^{* *}$ & $6.333 \mathrm{E}-09$ & 21.1977 \\
\hline & & 412.1 & 493.8 & & & \\
\hline & & 410 & 494.8 & & & \\
\hline & 1 & 410 & 494.8 & $64211.56^{* *}$ & $1.4551 \mathrm{E}-09$ & 21.1977 \\
\hline & & 410 & 493.8 & & & \\
\hline & & 409.5 & 494.8 & & & \\
\hline & 2 & 410.5 & 494.8 & $32232.61^{* *}$ & $5.7739 \mathrm{E}-09$ & 21.1977 \\
\hline & & 409.5 & 493.8 & & & \\
\hline & & 385.5 & 494.8 & & & \\
\hline & 6 & 385.5 & 494.8 & $106863.61^{* *}$ & $5.2537 \mathrm{E}-10$ & 21.1977 \\
\hline & & 385.5 & 493.8 & & & \\
\hline & & 375 & 494.8 & & & \\
\hline & 12 & 375 & 494.8 & $128450.56^{* *}$ & $3.6363 \mathrm{E}-10$ & 21.1977 \\
\hline & & 375 & 493.8 & & & \\
\hline & & 337.2 & 494.8 & & & \\
\hline \multirow[t]{17}{*}{$1: 1$} & 24 & 338.2 & 494.8 & $105093.27^{* *}$ & $5.4322 \mathrm{E}-10$ & 21.1977 \\
\hline & & 337.1 & 493.8 & & & \\
\hline & & 346.6 & 494.8 & & & \\
\hline & 48 & 347.6 & 494.8 & $97947.38^{* *}$ & $6.2537 \mathrm{E}-10$ & 21.1977 \\
\hline & & 346.6 & 493.8 & & & \\
\hline & & 316.4 & 494.8 & & & \\
\hline & 96 & 317.4 & 494.8 & $142151.12^{* *}$ & $2.969 \mathrm{E}-10$ & 21.1977 \\
\hline & & 316.4 & 493.8 & & & \\
\hline & & 282 & 494.8 & & & \\
\hline & 144 & 281 & 494.8 & $204416.18^{* *}$ & $1.436 \mathrm{E}-10$ & 21.1977 \\
\hline & & 281 & 493.8 & & & \\
\hline & & 268.4 & 494.8 & & & \\
\hline & 192 & 268.4 & 494.8 & $459955.24^{* *}$ & $2.836 \mathrm{E}-11$ & 21.1977 \\
\hline & & 268.4 & 493.8 & & & \\
\hline & & 261 & 494.8 & & & \\
\hline & 240 & 262 & 494.8 & $244580.18^{* *}$ & $1.003 \mathrm{E}-10$ & 21.1977 \\
\hline & & 261 & 493.8 & & & \\
\hline
\end{tabular}




\section{Continued}

\begin{tabular}{|c|c|c|c|c|c|c|}
\hline & & 376.3 & 494.8 & & & \\
\hline & 0 & 376.3 & 494.8 & $125670.25^{* *}$ & $3.799 \mathrm{E}-10$ & 21.1977 \\
\hline & & 376.3 & 493.8 & & & \\
\hline & & 377 & 494.8 & & & \\
\hline & 1 & 378 & 494.8 & $61390.08^{* *}$ & $1.592 \mathrm{E}-09$ & 21.1977 \\
\hline & & 378 & 493.8 & & & \\
\hline & & 374.7 & 494.8 & & & \\
\hline & 2 & 373.7 & 494.8 & $65268.85^{* *}$ & $1.408 \mathrm{E}-09$ & 21.1977 \\
\hline & & 373.7 & 493.8 & & & \\
\hline & & 352.6 & 494.8 & & & \\
\hline & 6 & 353.6 & 494.8 & $90142.58^{* *}$ & 7.383E-10 & 21.1977 \\
\hline & & 352.6 & 493.8 & & & \\
\hline & & 349 & 494.8 & & & \\
\hline & 12 & 350 & 494.8 & $94786.58^{* *}$ & $6.678 \mathrm{E}-10$ & 21.1977 \\
\hline & & 349 & 493.8 & & & \\
\hline & & 312.2 & 494.8 & & & \\
\hline $1: 2$ & 24 & 312.1 & 494.8 & $296246.53^{* *}$ & $6.837 \mathrm{E}-11$ & 21.1977 \\
\hline & & 312.1 & 493.8 & & & \\
\hline & & 306.3 & 494.8 & & & \\
\hline & 48 & 306.3 & 494.8 & $318660.25^{* *}$ & $5.909 \mathrm{E}-11$ & 21.1977 \\
\hline & & 306.3 & 493.8 & & & \\
\hline & & 278 & 494.8 & & & \\
\hline & 96 & 278 & 494.8 & $421720.36^{* *}$ & $3.374 \mathrm{E}-11$ & 21.1977 \\
\hline & & 278 & 493.8 & & & \\
\hline & & 278.1 & 494.8 & & & \\
\hline & 144 & 277.2 & 494.8 & $221885.34^{* *}$ & $1.219 \mathrm{E}-10$ & 21.1977 \\
\hline & & 277.1 & 493.8 & & & \\
\hline & & 261 & 494.8 & & & \\
\hline & 192 & 262 & 494.8 & $244580.18^{* *}$ & $1.003 \mathrm{E}-10$ & 21.1977 \\
\hline & & 261 & 493.8 & & & \\
\hline & & 258 & 494.8 & & & \\
\hline & 240 & 259 & 494.8 & $250915.28^{* *}$ & $9.53 \mathrm{E}-11$ & 21.1977 \\
\hline & & 258 & 493.8 & & & \\
\hline
\end{tabular}


2

1

0

6

12

$1: 3$

24

48

96

144

240

192

243

243

239.2

239.2

239.2
494.8

494.8

$194393.67^{* *}$

$1.588 \mathrm{E}-10$

21.1977

493.8

494.8

494.8

$193955.21^{* *}$

$1.595 \mathrm{E}-10$

21.1977

493.8

494.8

494.8

$200256.25^{* *}$

$1.496 \mathrm{E}-10$

21.1977

493.8

494.8

494.8

$208940.41^{* *}$

1.374E-10

21.1977

493.8

494.8

494.8

$279590.06^{* *}$

7.675E-11

21.1977

493.8

494.8

494.8

$261223.21^{* *}$

8.793E-11

21.1977

493.8

494.8

494.8

$271131.57^{* *}$

8.162E-11

21.1977

493.8

494.8

494.8

$404025.19^{* *}$

3.676E-11

21.1977

493.8

494.8

494.8

$207690.13^{* *}$

$1.391 \mathrm{E}-10$

21.1977

493.8

494.8

494.8

$569119.36^{* *}$

1.852E-11

21.1977

493.8

494.8

494.8

$586449.64^{* *}$

1.745E-11

21.1977

493.8 


\section{Continued}

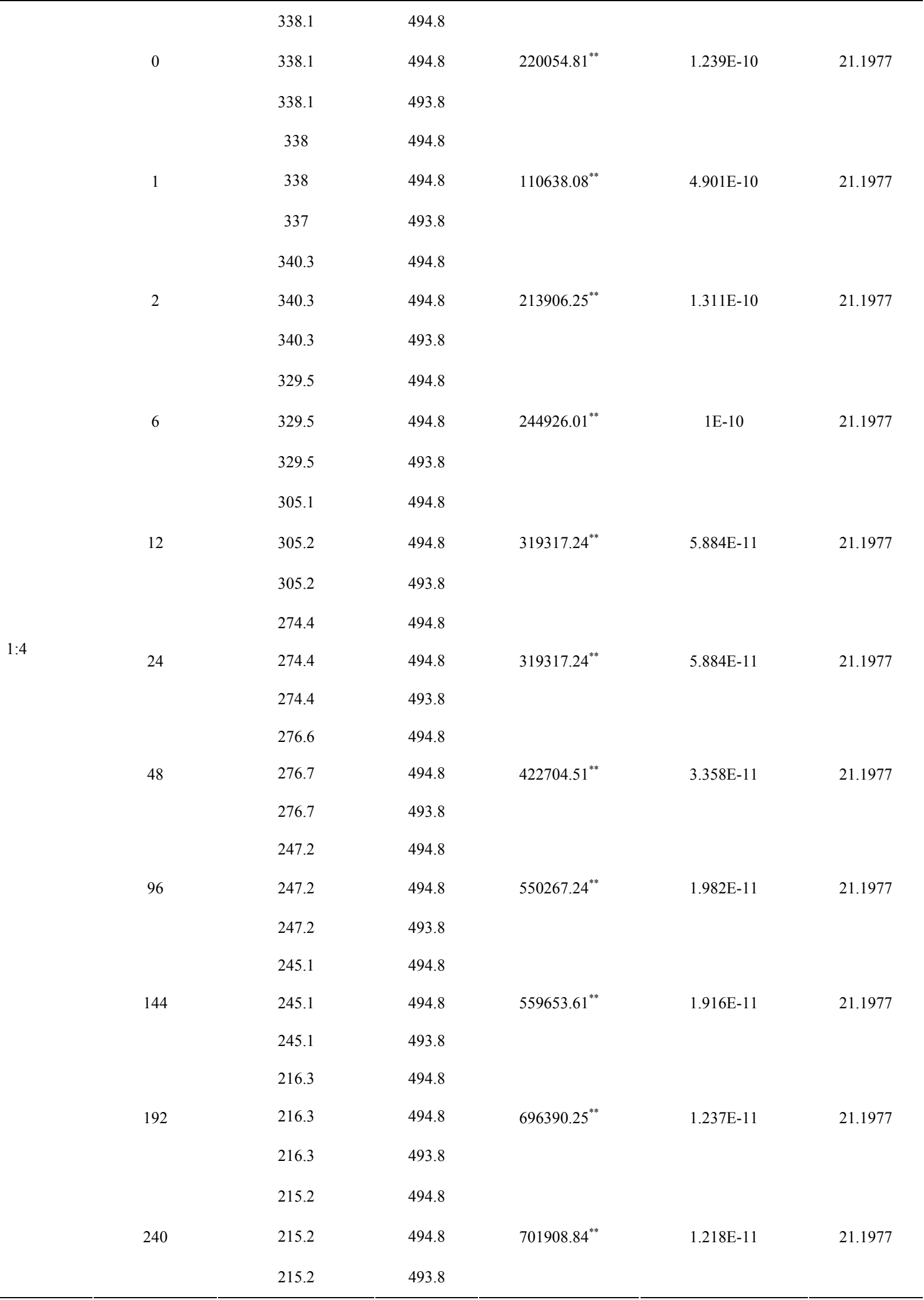




\begin{tabular}{|c|c|c|c|c|c|c|}
\hline & \multirow{3}{*}{0} & 336.7 & 494.8 & \multirow{3}{*}{$224012.89^{* *}$} & \multirow{3}{*}{$1.196 \mathrm{E}-10$} & \multirow{3}{*}{21.1977} \\
\hline & & 336.7 & 494.8 & & & \\
\hline & & 336.7 & 493.8 & & & \\
\hline & \multirow{3}{*}{1} & 336.4 & 494.8 & \multirow{3}{*}{$222451.49^{* *}$} & \multirow{3}{*}{$1.212 \mathrm{E}-10$} & \multirow{3}{*}{21.1977} \\
\hline & & 336.5 & 494.8 & & & \\
\hline & & 336.5 & 493.8 & & & \\
\hline & \multirow{3}{*}{2} & 338.1 & 494.8 & \multirow{3}{*}{$220054.81^{* *}$} & \multirow{3}{*}{$1.239 \mathrm{E}-10$} & \multirow{3}{*}{21.1977} \\
\hline & & 338.1 & 494.8 & & & \\
\hline & & 338.1 & 493.8 & & & \\
\hline & \multirow{3}{*}{6} & 319.9 & 494.8 & \multirow{3}{*}{$274261.69^{* *}$} & \multirow{3}{*}{$7.976 \mathrm{E}-11$} & \multirow{3}{*}{21.1977} \\
\hline & & 319.9 & 494.8 & & & \\
\hline & & 319.9 & 493.8 & & & \\
\hline & \multirow{3}{*}{12} & 307.7 & 494.8 & \multirow{3}{*}{$313936.09^{* *}$} & \multirow{3}{*}{$6.088 \mathrm{E}-11$} & \multirow{3}{*}{21.1977} \\
\hline & & 307.7 & 494.8 & & & \\
\hline & & 307.7 & 493.8 & & & \\
\hline & \multirow{3}{*}{24} & 280.3 & 494.8 & \multirow{3}{*}{$205761.13^{* *}$} & \multirow{3}{*}{$1.417 \mathrm{E}-10$} & \multirow{3}{*}{21.1977} \\
\hline \multirow[t]{17}{*}{$1: 5$} & & 280.3 & 494.8 & & & \\
\hline & & 281.3 & 493.8 & & & \\
\hline & \multirow{3}{*}{48} & 279.5 & 494.8 & \multirow{3}{*}{$415896.01^{* *}$} & \multirow{3}{*}{$3.469 \mathrm{E}-11$} & \multirow{3}{*}{21.1977} \\
\hline & & 279.5 & 494.8 & & & \\
\hline & & 279.5 & 493.8 & & & \\
\hline & & 238.8 & 494.8 & & & \\
\hline & 96 & 238.8 & 494.8 & $588289.00^{* *}$ & $1.734 \mathrm{E}-11$ & 21.1977 \\
\hline & & 238.8 & 493.8 & & & \\
\hline & & 240.2 & 494.8 & & & \\
\hline & 144 & 240.2 & 494.8 & $581863.84^{* *}$ & $1.772 \mathrm{E}-11$ & 21.1977 \\
\hline & & 240.2 & 493.8 & & & \\
\hline & & 207 & 494.8 & & & \\
\hline & 192 & 207 & 494.8 & $743733.76^{* *}$ & $1.085 \mathrm{E}-11$ & 21.1977 \\
\hline & & 207 & 493.8 & & & \\
\hline & & 206.4 & 494.8 & & & \\
\hline & 240 & 206.4 & 494.8 & $746841.64^{* *}$ & $1.076 \mathrm{E}-11$ & 21.1977 \\
\hline & & 206.4 & 493.8 & & & \\
\hline
\end{tabular}

${ }^{* *}$ Significance of difference is at the $P<0.01$ level; ${ }^{*}$ Significance of difference is at the $P<0.05$ level. 